\title{
Power system voltage collapse prediction using a new line stability index (NLSI-1): A case study of the 330-kV Nigerian National Grid
}

\author{
I. A. Samuel ${ }^{1}$, J. Katende ${ }^{2}$, C. O. A. Awosope ${ }^{3}$, A. A. Awelewa ${ }^{4}$, A. I. Adekitan ${ }^{5}$, F. A. Agbetuyi ${ }^{6}$ \\ ${ }_{1,3,4,5,6}$ Department of Electrical and Information Engineering, Covenant University, Nigeria \\ ${ }^{2}$ Department of Electrical and Computer Engineering, Namibia University of Science and Technology, Namibia
}

\begin{tabular}{l}
\hline Article Info \\
\hline Article history: \\
Received Aug 24, 2018 \\
Revised Apr 24, 2019 \\
Accepted Jul 17, 2019 \\
\hline
\end{tabular}

\section{Keywords:}

Line stability index New line stability index Nigerian national grid Power system, voltage collapse Voltage stability indices

\begin{abstract}
The cumulative number of historical and recent power system outages substantiates the fact that further studies are necessary for an improved solution to the issue of voltage instability on the grid and the subsequent system collapse. Voltage collapse is a serious reliability issue which inhibits the objective of running a reliable and secure power system network. In this study, a new line stability index (NLSI_1) for predicting voltage collapse is presented. The new index considers a switching logic which is derived from the difference of voltage angle between the two load buses. The index is deployed for performance analysis using the 28-bus, 330-kV Nigeria National Grid (NNG). The simulation implemented in MATLAB shows that the index gives the same results as Line stability index (Lmn) and Fast Voltage Stability Index (FVSI) indices. The base case and the contingency scenarios were considered during the simulation. The base case analysis using the NNG values of all the three indices FVSI, Lmn, and NLSI_1 for simulation generates a value less than one for the entire lines which implies that the NNG is stable in this mode. The values of the three indices are almost the same, which confirms the accuracy of the novel index developed. The analysis for the contingency case reveals that the load bus 16 (Gombe) which has the lowest, maximum permissible reactive load of $139.5 \mathrm{MVAR}$ is the weakest; also power line 16-19 is identified as the critical line. The result of the simulation confirms that the accuracy was improved by using NLSI_1.
\end{abstract}

Copyright $(2019$ Institute of Advanced Engineering and Science. All rights reserved.

\section{Corresponding Author:}

I. A. Samuel,

Department of Electrical and Information Engineering,

Covenant University,

KM 10, Idiroko Road, P. M. B 1023, Ota, Ogun State, Nigeria.

Email: isaac.samuel@covenantuniversity.edu.ng

\section{INTRODUCTION}

As defined by P. Kundur [1], Voltage stability is the capacity of power system network (PSN) to ensure a stable voltage level within acceptable limits, on all the buses in the PSN at normal operating conditions after experiencing a network disturbance. Under normal operating conditions, a power system should maintain its equilibrium state in the event of an operational perturbation; the power system should be automatically restored to stable conditions after the system disturbances. When a gradual and unrestrained drop in line voltage occurs as a result of disturbances on the power system network (PSN), the power network is said to be in a state of instability [2]. In a power system, voltage instability occurs when there is an outage on a generator or a power line as a result of a fault, a sudden load increase, or an inappropriate control of voltage regulating devices. Voltage instability can also be triggered by discrepancies in reactive power demand and supply. When voltage instability on a PSN due to extreme load is allowed to persist 
unresolved, it will result in a drop in system voltage which will ultimately lead to voltage collapse with the resultant system blackout, either partial or total. This threatens power system security and therefore impedes the goal of ensuring an uninterrupted and reliable supply of electricity to energy consumers [3]. As a result of wide-scale economic and environmental limitations, PSN in Nigeria is being operated at the borderline of their transmission capacity limits [4].

According to a world bank report, the yearly losses as a result of blackouts experienced in Nigeria was estimated at $\$ 100$ billion [5]. Consequently, a number of investors are cautious of investing in Nigeria due to the daily power outages that creates a major economic challenge [6]. A number of industries in Nigeria closed down as a result of inadequate power supply which has made business operation and survival severely tough for both small scale businesses and manufacturers [7, 8].

Although, there is a high frequency of voltage collapse on the Nigerian National Grid yearly the available research work on the issue is quite a few. About 30 system collapses were recorded annually within a ten year period ranging from January 2005 to December 2014, this is quite enormous and it renders the national grid insecure and unreliable. About $88 \%$ of the disturbances accountable for this system collapses are fault-induced, and this, therefore, implies that the Nigeria National Grid is not robust and therefore susceptible to voltage instability and collapse [7]. Comparing the frequency of occurrence of voltage collapses globally and on the NNG as shown in Figure 1, reveals that the NNG experiences more voltage collapses than what is obtains globally. This brings to bear the enormity of the problem on the NNG system and therefore, the need arises to investigate and predict voltage collapse to ensure reduction and mitigate voltage collapse on the network to improve its overall efficiency and effectiveness [9]. The unbundling of power system also place limitations on its expansion, this results in the operation of transmission lines close to their limits leading to more power outages and system collapses [10, 11]

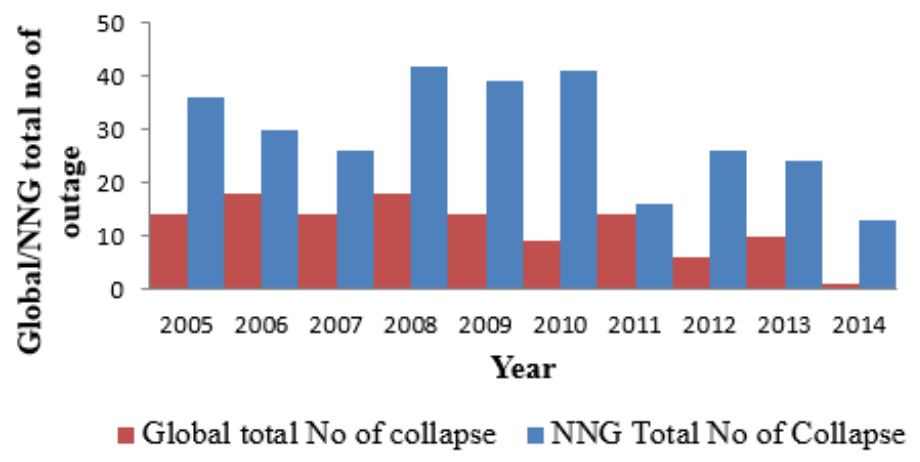

Figure 1. Comparing voltage collapse globally as against its occurrence on the NNG [9]

In this study, the performance of a new voltage stability index is evaluated by deploying it on a real PSN. With respect to the fact that the variation between the voltage angles of two load buses can trigger a PSN voltage collapse [12], the proposed New Line Stability Index-1 referred to as NLSI_1 integrates a switching logic which is derived from the difference in the voltage angles of the 2 load buses. The index is deployed for performance evaluation using the 28-bus, 330-kV Nigeria National Grid (NNG). During the performance analysis in the MATLAB environment, the base case and the contingency scenarios were considered.

\section{VOLTAGE STABILITY INDICES}

A number of tools termed voltage stability indices are available for determining whether a system voltage is stable, and if not stable the extent to which the system is to instability. The indices reveal the critical bus of a PSN and also the stability status of each of the power lines connected in between two buses in an interconnected PSN [13, 14].

The loading margin of a PSN can be determined using the Power-Voltage (P-V) curves while the Reactive Power-Voltage $(\mathrm{Q}-\mathrm{V})$ curve is a suitable index for assessing voltage instability. In the Q-V curve, the voltage stability limit is defined as the point where the $\mathrm{dQ} / \mathrm{dV}$ is zero. The point where the power curve intersects the horizontal axis is the operating point, and at this point, there is no need to inject or absorb any reactive power [15-17]. The eigenvectors and eigenvalues of the system's reduced power flow Jacobian 
matrix can be used in the modal analysis to deduce the voltage stability of a power system [18, 19]. For steady-state analysis, a PSN has a stable voltage provided the eigenvalues obtained from the reduced power-flow Jacobian matrix are all positive, if there are any negative eigenvalues then the system is unstable $[19,20]$. If the eigenvalue is zero $(0)$, then it implies that the power system is only marginally stable and at the boundary line of voltage collapse and this creates a high probability for voltage instability to ensure [21].

Using the modal analysis, the QV, the PV, and the energy-based procedures as suggested by [22, 23] is quite intensive to compute, it is time-consuming and rigorous whereas voltage collapse prediction demands6a fast response. It is therefore imperative to use a reduced calculation time, less tedious and easy to deploy voltage stability indices for either offline or online PSN collapse prediction for improved performance and response.

\section{COMMON LINE VOLTAGE STABILITY INDICATORS} previous studies:

The following highlights the 4 major voltage stability indices that have been applied by

\subsection{Line stability index (Lmn)}

The idea of the Lmn is derived from the single line power transmission concept. It was developed for evaluating the stability of a power line connecting two buses in an interconnected system which has been scaled down to a single line PSN. Lmn is expressed as follows:

$$
L_{m n}=\frac{4 X Q_{r}}{\left|V_{s}\right|^{2} \sin ^{2}(\theta-\delta)} \leq 1
$$

For interpretation purposes, if the Lmn index is close to 1, the line in the PSN is deemed close to instability but the system is said to be stable when the Lmn value is less than 1 [24].

\subsection{Fast voltage stability index (FVSI)}

The use of the FVSI was proposed in the study by [25]. The FVSI like the Lmn also applies the concept of power flow through a single line [11]. The FVSI was developed using the standard line current equation for a line connected between two buses. It is mathematically defined as follows:

$$
F V S I=\frac{4 Z Q_{r}}{V_{s}^{2} X} \leq 1
$$

The most critical line in a bus is the line that has a stability index value that is closest to one (1) and such a bus has the tendency to trigger system instability [26]. In deriving the index, an assumption is made that the difference between the voltage angles of the two load buses is quite small.

\subsection{Line stability factor (LQP)}

The LQP was developed by [27], by applying a method for fixing the discriminant of the power quadratic equation at a value that is $\geq 0$. The LQP index is defined as:

$$
L Q P=4\left(\frac{X}{V_{s}^{2}}\right)\left(\frac{X}{V_{s}^{2}} p_{s}+Q_{r}\right)
$$

The value of the LQP index for a stable system must be kept below 1 otherwise it may trigger a voltage collapse.

\subsection{Line voltage stability index (LVSI)}

The LVSI is based on the relationship existing between the bus voltage and the line's real power [14]. In this model, a failure ensues when the line resistance of the power line reduces to a near zero value. The LVSI is defined in (4). 


$$
L V S I=\frac{4 R P_{r}}{\left[V_{s} \cos \theta-\delta\right]} \leq 1
$$

The Line Voltage Stability Index is extra sensitive to $\delta$, and this is because $\cos (\theta-\delta)$ is faster than $\sin (\theta-\delta)$ in the $90^{\circ}$ region and this creates a tendency for identifying a healthy line as a critical line [28]. Note that in the expression in (4), all the symbols do not have their usual meanings.

\section{NEW LINE STABILITY INDEX_1 (NLSI-1)}

To derive the NLSI-1 the power system model of a two-bus network using the single line diagram as shown in Figure 2 is considered. All the variables and parameters are given in per unit.

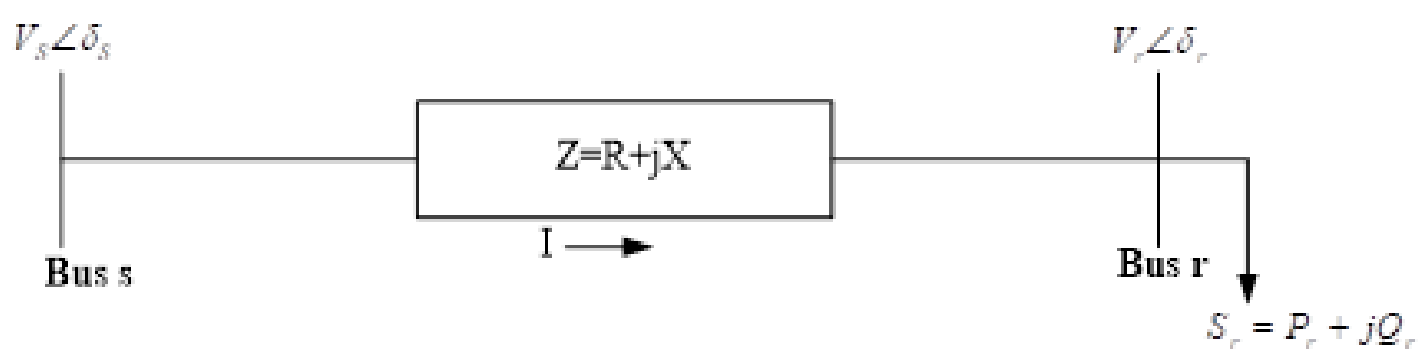

Figure 2. The single line model of a 2-bus power system

As shown in Figure 1, bus's' (the reference bus) and bus ' $r$ ' are the sending end and the receivingend bus respectively. The model variables are explained as follows: $\mathrm{V}_{r}$ and $\mathrm{V}_{s}$ are the receiving end and the sending end bus voltage, $\mathrm{P}_{\mathrm{r}}$ and $\mathrm{S}_{\mathrm{r}}$ are the real power and the reactive power respectively at the receivingend bus ' $r$ '; $\delta_{r}$ and $\delta_{s}$ are the voltage angles of the receiving-end and sending-end buses respectively; $\delta$ stands for the difference between $\delta \mathrm{r}$ and $\delta$ s.

According to the study by [12], wide angular differences may portend a higher risk of a system collapse. This, therefore, necessitates the use of the NLSI_1 which incorporates a switching function, $\sigma$, and logic for computing the proximity of voltage collapse in order to enhance the precision of stability assessment. The NLSI_1 is defined as:

$$
N L S I_{-} 1=\frac{4 Q_{r}}{\left|V_{s}\right|^{2}}\left[\frac{|Z|^{2}}{X} \sigma-\frac{X}{\sin ^{2}(\theta-\delta)}(\sigma-1)\right] \leq 1 \quad \sigma= \begin{cases}1 & \delta<\delta_{c} \\ 0 & \delta \geq \delta_{c}\end{cases}
$$

In (5), $\sigma$ is the switching function while $\delta$ is a modifier. The value of $\sigma$ depends on the magnitude of the angular difference $\delta$. From the load-flow program, the value of $\delta$ is computed and verified against a baseline value, $\delta_{c}$ so as to determine if $\sigma$ is 1 or 0 . The system voltage will be stable if NLSI-1 is below 1 . The closer the value of NLSI-1 gets to 1 the higher the risk of a voltage collapse. This index helps in ensuring optimal allocation of compensation devices towards mitigating voltage collapse by helping to identify the most vulnerable and weakest line bus [9, 29].

\section{THE NIGERIA NATIONAL GRID 28-BUS, 330-KV NETWORK}

The diagram in Figure 3 shows the NNG, 28-Bus, 330-kV Network which has nine (9) generator (PV) buses, nineteen (19) Load (PQ) buses and thirty-one (31) interconnected branches. In most parts of the network, the NNG is characterized by low voltages as a result of the insufficient dispatch and control infrastructures [30]. The NNG is a radial grid; it is weak and overloaded which culminates in high transmission losses and incessant network collapse [31]. As a result of these factors, the NNG is weak and highly stressed which makes it vulnerable to voltage instability and the eventual system collapse [7, 32]. 


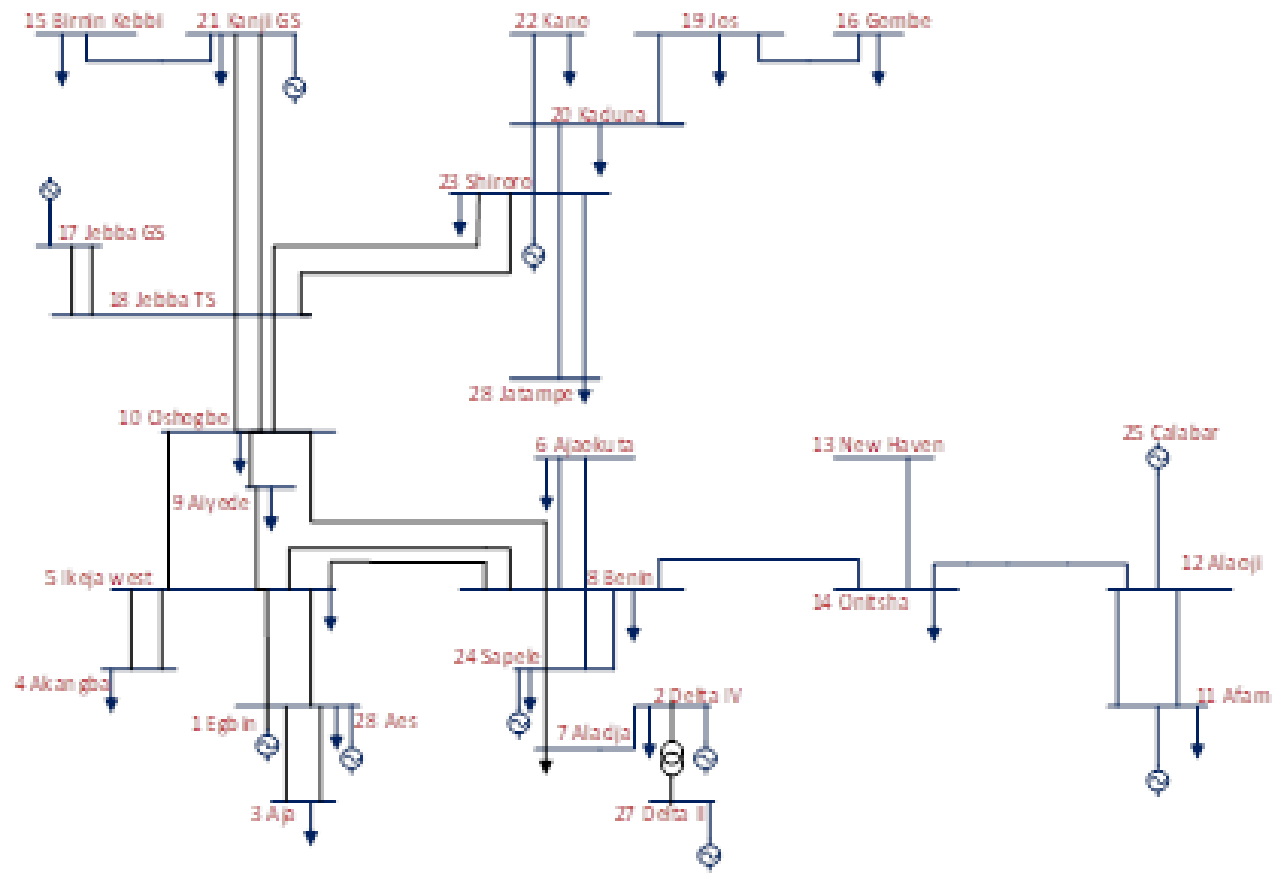

Figure 3. The diagram of the 28-bus, 330-kV NNG network [33, 34]

\section{RESULTS AND ANALYSIS}

\subsection{The results of the power flow simulation using the NNG 28-bus, 330-kV network}

A 2-case scenario, power flow simulation was deployed for the NNG 28-bus, 330-kV network. These analyses were carried out to determine the voltage stability indices for the base case and the contingency case for the network. The Egbin thermal power station bus has the largest power generator as compared with the other generating stations, and also it has the lowest power mismatch, and this informs its selection as the slack bus for the load flow analysis [35]. The voltage profile of the NNG is shown in Figure 4.

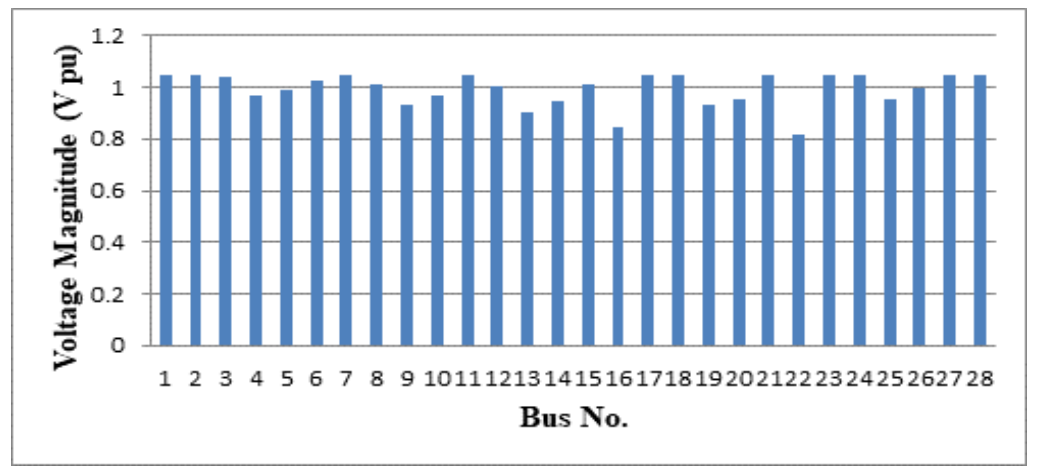

Figure 4. A chart showing the voltage magnitude on each bus of the 28-bus NNG

\subsection{The results of the power flow simulation for the 28-bus NNG System}

To carry out the voltage stability simulations, it is vital to determine the switching function $\sigma$ which is unique to the network. In order to choose the least error different point for the switching function $\sigma$, the percentage error between the FVSI and Lmn index was determined. The switching function $\sigma$ selected has a percentage error of 2.379 within an equivalent angular difference of $4.076^{\circ}$. This is to allow for immediate switching to Lmn index if the voltage angle difference goes above $4.076^{\circ}$ and then switch back to the FVSI index when it falls below $4.076^{\circ}$. 
Result for the base case scenario is depicted in the bar chart of Figure 5 which shows comparatively the values of Lmn, FVSI and NLSI_1 in a bar chart for the 31 interconnected lines of the NNG 330-kV, 28-bus network. As shown by the chart, all the line stability indices values for the thirty-one lines are below one (1) which implies that the system is stable. The magnitudes of the three indices are almost equal and this observation confirms the fact that NLSI_1 index which is newly developed can serve as an alternative to the other two indices.

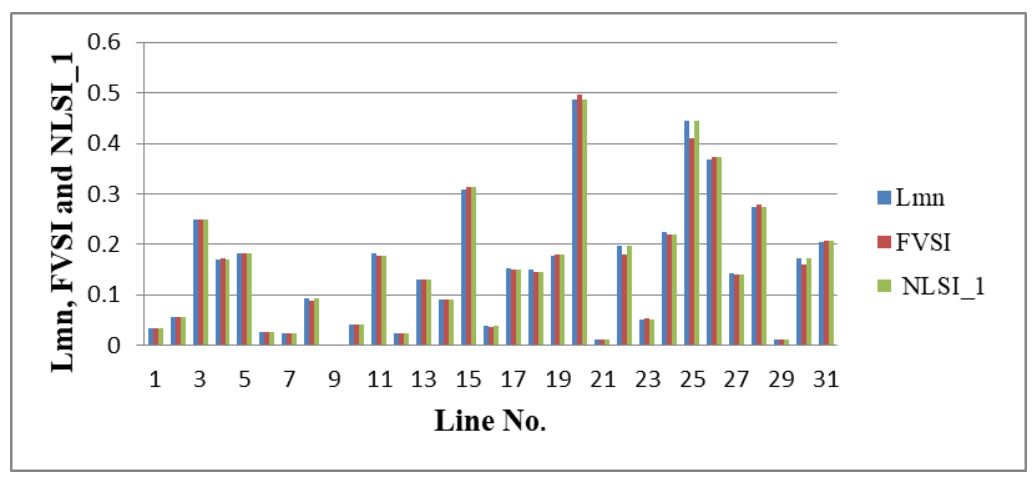

Figure 5. A chart showing Lmn, FVSI and NLSI_1 for each transmission line

For the second case study i.e. the contingency scenario, the impact of reactive load variations on the NNG bus was determined by varying the reactive loads on the load buses one by one. This was done in order to determine the maximum reactive load for each bus and also to identify the weakest bus and the critical line. The maximum reactive load of each bus in MVAr is plotted in Figure 6 against the bus number. The Load bus 16 has the lowest maximum permissible reactive load of $139.5 \mathrm{MVAr}$ and this makes it the weakest and the most susceptible bus to voltage collapse. Since the bus only has one connected line, therefore line 16-19 is the critical line and this means that a voltage collapse will ensue if there is any additional reactive load to the line.

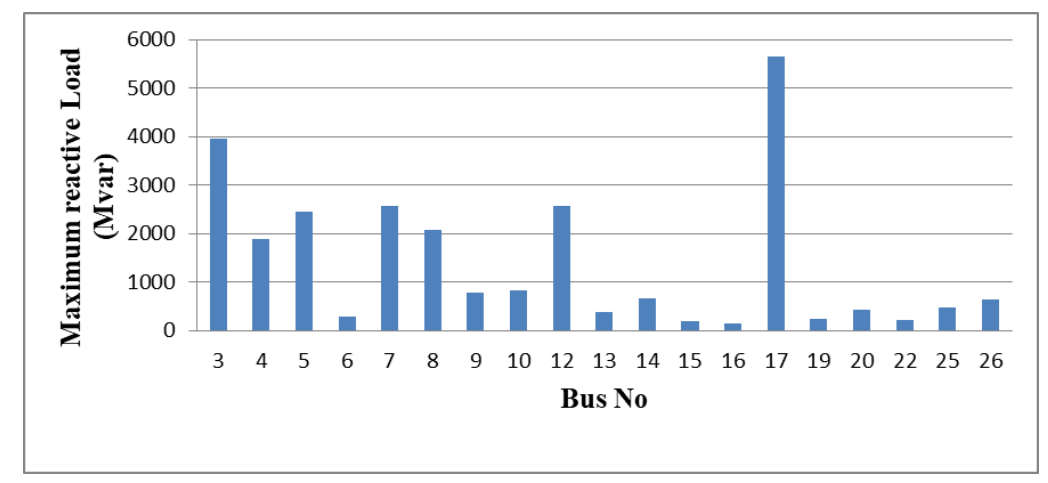

Figure 6. The maximum reactive loads $(\mathrm{Q})$ at the load buses of the NNG

The reactive power on the critical bus 16 (Gombe) was varied to reveal the effects of the per-unit voltage magnitude, and FVSI, Lmn and NLSI_1 (16-19). The result of the analysis is presented in Table 1. The chart of Vmag, FVSI, Lmn and NLSI_1 plotted against the reactive load variation on bus 16 is detailed in Figure 7. From the results presented in Figure 7 for the weakest bus 16, it shows that there is a drop in the voltage magnitude with increasing reactive power, simultaneously the voltage stability indices also increased until voltage collapse occurs. As revealed by the results, the NLSI_1 gives an accurate representation of FVSI and the Lmn indices and as such it could be used in place of either the Lmn or FVSI for enhancing the voltage stability evaluation of power system networks. Figure 6 shows that the curve of Lmn almost overlaps that of NLSI_1 which makes the curves appear as one line. This confirms that the novel index NLSI_1 compares satisfactorily well with the Lmn or FVSI indices. 
Table1. The variations of the reactive power on load bus 16

\begin{tabular}{cccccc}
\hline S/No & Q $($ MVAr & Vmag $(\mathrm{pu})$ & Lmn & FVSI & NLSI_1 \\
\hline 1 & 0 & 1.028 & 0 & 0 & 0 \\
2 & 15 & 1.005 & 0.05272 & 0.05364 & 0.05272 \\
3 & 30 & 0.98 & 0.11077 & 0.11273 & 0.11077 \\
4 & 45 & 0.954 & 0.17535 & 0.17845 & 0.17535 \\
5 & 60 & 0.926 & 0.24807 & 0.25246 & 0.24807 \\
6 & 75 & 0.896 & 0.33128 & 0.33714 & 0.33128 \\
7 & 90 & 0.863 & 0.42857 & 0.43614 & 0.42857 \\
8 & 105 & 0.826 & 0.54588 & 0.55549 & 0.54588 \\
9 & 120 & 0.783 & 0.69438 & 0.70646 & 0.69438 \\
10 & 135 & 0.73 & 0.9 & 0.91519 & 0.9 \\
11 & 139.5 & 0.71 & 0.98229 & 0.99859 & 0.98229 \\
\hline
\end{tabular}

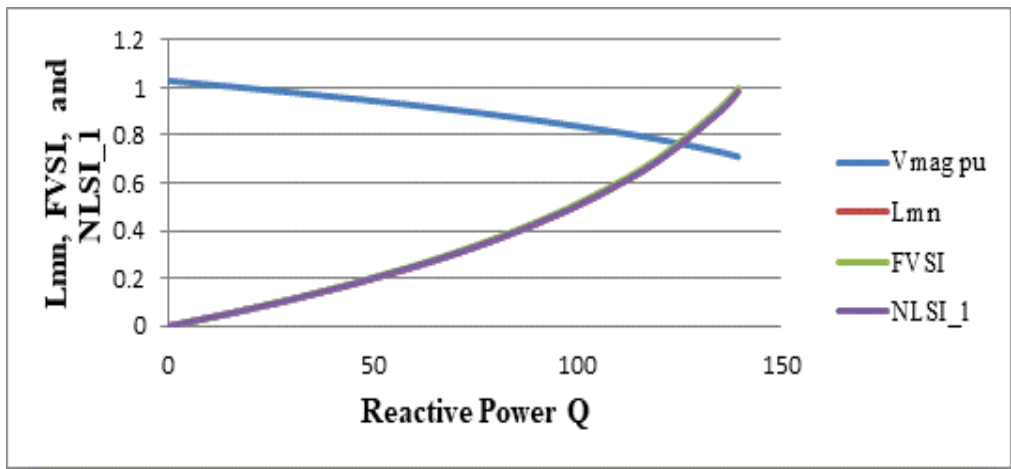

Figure 7. A chart showing the indices and the reactive power variations on bus 16

\section{CONCLUSION}

In this study, an improvement in voltage collapse prediction on a power grid was achieved by the application of a new line stability index-1 (NLSI_1) using the Nigeria National Grid 330kV, 28-bus network for performance evaluation. The functionality and performance validation of NLSI_1 shows that the index performed comparatively well with respect to the two existing indices (Lmn and FVSI). For voltage collapse prediction and for the identification of the weakest bus and also the critical line in a power system network, the NLSI_1 is computationally efficient and very effective. Also, by using the new index compensation devices can be optimally placed so as to prevent voltage collapse.

\section{ACKNOWLEDGEMENTS}

The Covenant University Centre for Research, Innovation and Discovery is highly appreciated by the Authors for supporting the publication of this article.

\section{REFERENCES}

[1] P. Kundur., Power System Stability and Control, McGraw-Hill, 1994.

[2] K. S. Sarat, S. R. Suresh and S.V. Jayaram Kumar., "New Voltage Stability Index (NVSI) for Voltage Stability Analysis in Power System," International Journal of Electrical and Electronics Engineering Research (IJEEER), vol. 2(4), pp. 13-20, 2012.

[3] J. Veleba, and T. Nestorovic, "Performance of Static Voltage Stability Analysis in MATLAB Environment with Further Applications," International journal of education and information technologies, vol. 4(7), pp. 133-145, 2013.

[4] N. A. Ali., "An Overview of system collapses on the Nigerian Grid Network," In Proceedings of the International Conference on Power Systems Operations and Planning-VI (ICPSOP), pp. 67-70, May 2005.

[5] Channelstv, "Nigeria Loses \$100 Billion To Daily Blackout," Channels, 2015, from [Online] Available: http://www.channelstv.com/: http://www.channelstv.com/2015/09/13/nigeria-loses-100-billion-to-daily-blackout/, [Retrieved June 08, 2016].

[6] Ogbonna, A., Nigeria loses \$100b to a daily power outage. vanguard, pp. 1, 2015.

[7] I. A. Samuel, J. Katende, S. A. Daramola, and A. A. Awelewa., "Review of System Collapse Incidences on the 330-kV Nigerian National Grid," International Journal of Engineering Science Invention, vol. 3, pp. 55-59, 2014. 
[8] Adeyinka Ajao Adewale, Aderibigbe Israel Adekitan, Ofukowoicho Jeremiah Idoko, Felix Ayoade Agbetuyi and Isaac Adekunle Samuel., "Energy audit and optimal power supply for a commercial building in Nigeria," Cogent Engineering, vol. 5, pp. 1-18, 2018.

[9] I. A. Samuel, "A New Voltage Stability Index for Predicting Voltage Collapse In Electrical Power System Networks," Covenant University, PhD Theses. eprints.covenantuniversity.edu.ng/9498, 2017.

[10] Raghu C. N, and A. Manjunatha, "Assessing Effectiveness of Research for Load Shedding in Power System," International Journal of Electrical and Computer Engineering (IJECE), vol. 7(6), pp. 3235-3245, Dec 2017.

[11] Prakash Kumar Hota and Atulya Prasad Naik, "A New Methodology for Active Power Transmission Loss Allocation in Deregulated Power System," International Journal of Electrical and Computer Engineering (IJECE), vol. 7(4), pp. 1725-1727, Aug 2017.

[12] I. Dobson, M. Parashar, and C. Carter., "Combining phasor measurements to monitor cutset angles," In System Sciences (HICSS), 2010 43rd Hawaii International Conference on, IEEE, Jan 2010, pp. 1-9.

[13] I. Kumarswamy, and P. Ramanareddy, "Analysis of Voltage Stability Using L-Index Method," International Journal of Electrical Engineering, vol. 4(4), pp. 483-498, 2011.

[14] M. Mathew, D. S. Babu, P. S. Venkataramu, and M. S. Nagaraj., "Effect of TCSC on Line Voltage Stability Indices under Single Line Outage Condition," International Journal Of Innovative Research in Electrical, Electronics, Instrumentation and Control Engineering, vol. 3(8), pp. 101-105, 1998.

[15] S. Bhaladhare, A. Telang, and P. Bedekar., "PV, QV Curve-A Novel Approach for Voltage Stability Analysis," International Journal of Computer Applications (IJCA), 2013.

[16] V. Balamourougan, T. S. Sidhu, and M. S. Sachdev., "Technique for online prediction of voltage collapse," IEE Proceedings-Generation, Transmission and Distribution, vol. 151(4), pp. 453-460, 2004.

[17] M. Sanaye-Pasand, and A. Rezaei-Zare, "Review and Simulation of Static Indices in Detection of Proximity to Voltage Collapse," In Australian Universities Power Engineering Conference, 2003.

[18] H. H. Goh, Q. S. Chua, S. W. Lee, B. C. Kok, K. C. Goh, and K. T. K, Teo., "Comparative study of line voltage stability indices for voltage collapse forecasting in power transmission system," Rio de Janeiro Brazil, vol. 13(2), pp. 270-275, 2015.

[19] T. Bhawana and K. Prabodh, "Voltage Stability Evaluation Using Modal Analysis," International Journal of Scientific Research Engineering \& Technology (IJSRET), vol. 4(4), pp. 408-411, 2015.

[20] F. Enemuoh, J. Onuegbu, and E. Anazia., "Modal Based Analysis and Evaluation of Voltage Stability of Bulk Power System," vol. 6, pp. 71-79, 2013.

[21] I. C. Gunadin., "Steady State Stability Assessment Using Extreme Learning Machine Based on Modal Analysis," International review of Electrical Engineering, vol. 7, 2013.

[22] M. Hasani, and M. Parniani, "Method of combined static and dynamic analysis of voltage collapse in voltage stability assessment," In 2005 IEEE/PES Transmission \& Distribution Conference \& Exposition: Asia and Pacific, IEEE, 2005, pp. 1-6.

[23] M. Nizam, A. Mohamed, and A. Hussain., "Voltage collapse prediction incorporating both static and dynamic analyses, "European Journal of Scientific Research, vol. 16(1), pp. 10-25, 2007.

[24] M. Moghavvemi, and F. M. Omar, "Technique for contingency monitoring and voltage collapse prediction," IEE Proceedings-Generation, Transmission and Distribution, vol. 145(6), pp. 634-640, 1998.

[25] I. Musirin, and T. A. Rahman, "Novel fast voltage stability index (FVSI) for voltage stability analysis in the power transmission system," In Research and Development, 2002. SCOReD 2002. Student Conference on, IEEE, 2002, pp. 265-268.

[26] K. R. Vadivelu, and D. G. Marutheswar, "Maximum Load-ability Estimation for Weak Bus Identification Using Fast Voltage Stability Index in a Power Transmission System by Real-Time Approach," International Journal of Electrical and Electronics Engineering \&Telecommunications, 2014.

[27] A. Mohamed, G. B. Jasmon and S. Yusoff., "A static voltage collapse indicator using line stability factors," Journal of industrial technology, vol. 7(1), pp. 73-85, 1989.

[28] M. Haruna, "An Overview on Voltage Stability Indices as Indicators of Voltage Stability for Networks with Distributed Generations Penetration," International Journal of Science, Technology and Society, vol. 3(4), pp. 214-219, 2015.

[29] I. A. Samuel, J. Katende, C. O. A. Awosope, A. A. Awelewa., "Prediction of Voltage Collapse in Electrical Power System Networks using a New Voltage Stability Index," International Journal of Applied Engineering Research, vol. 12(2), pp. 190-199, 2017.

[30] A. G. Adebayo, A. Jimoh, A. Yusuff and Adeyemi, "An Effects Of Phase Shifting Transformers On Weak And IllConditioned Network: Nigerian 330kv Grid System," Power, 13, 14. International Conference of power and Energy Systems (Africa PSE 2014). Gaboroune, Botswana. 2014.

[31] Nigeria Electricity Regulatory Commission, the Grid Code for the Nigeria Electricity Transmission System, Electrical power sector reform Act, version 01.2005, 2005.

[32] O. O. Onahaebe, and S. Apeh, "Voltage Instability in Electrical Network: A case study of Nigerian 330kV Transmission Grid," Research Journal of Applied Sciences, vol. 2(8), pp. 865-874, 2007.

[33] O. O. Sunday., "Power outages in the Nigeria transmission grid," Research Journal of Applied Sciences, vol. 4(1), pp. 1-9, 2009.

[34] TCN, Daily Operational Report, Osogbo: Transmission Company of Nigeria (TCN), 2015. 
[35] I. A. Samuel, N. M. Okwechime and A. Abdulkareem., "Investigating the Selection of A Suitable Slack Bus: A Case Study of the Multi-Generating Stations of the Nigerian 330-Kv Power System Network, " International Journal of Electrical Electronic Engineering Studies, vol. 2(1), pp. 1-12, 2014.

\section{BIOGRAPHY OF AUTHORS}
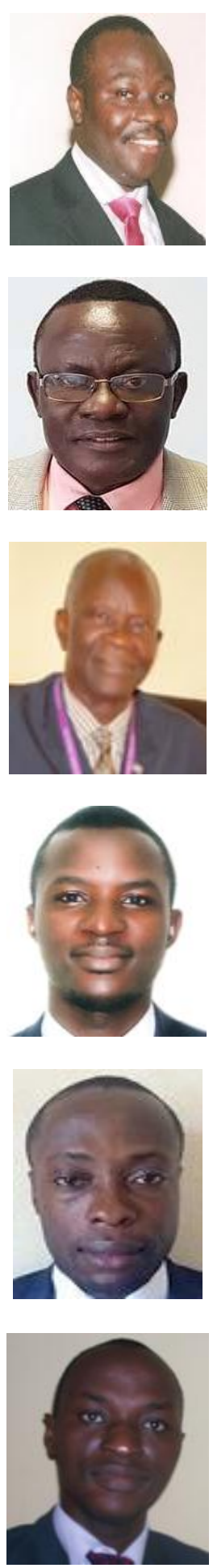

I. A. Samuel obtained his PhD Electrical and Electronics Engineering from Covenant University, Ota, Nigeria, where he is currently a Senior Lecturer in the Department of Electrical \& Information Engineering. His research areas include power system voltage stability and operation, reliability, and maintenance.

J. Katende is a Professor of Electrical Engineering and a lecturer in Department of Electrical and Computer Engineering, Namibia University of Science and Technology, Windhoek, Namibia. His research areas include Robotics and automation; power system and control; modelling and simulation of dynamical systems; and renewable energy.

C. O. A. Awosope is a Professor of Electrical Engineering and a lecturer in the Department of Electrical \& Information Engineering, Covenant University, Ota. His research areas include Power system reliability, operation and maintenance.

A. A. Awelewa obtained his PhD Electrical and Electronic Engineering from Covenant University, Ota, Nigeria, where he is currently a Senior Lecturer in the Department of Electrical \& Information Engineering. His research areas include power system stabilization and control, and modelling and simulation of dynamical systems.

A. I. Adekitan is a PhD student studying Electrical /Electronics Engineering.and a lecturer in the Department of Electrical \& Information Engineering, Covenant University, Ota. His research area includes power system, operation and reliability.

F. A. Agbetuyi obtained his $\mathrm{PhD}$ Electrical and Electronics Engineering from Covenant University, Ota, Nigeria, where he is currently a Senior Lecturer in the Department of Electrical \& Information Engineering. His research areas include Renewable Energy, microgrid, power system stability simulation of dynamic systems and distributed generation. 